\title{
Characterization of Isolated Candida Spp in Blood Stream Infection and its Antifungal Susceptibility Pattern
}

\author{
Meghagevariya and Ekta Gosaliya* \\ Department of Microbiology, P.D.U Medical College, Rajkot-360001, Gujarat, India \\ *Corresponding author
}

\begin{tabular}{|l|}
\hline K e y w o r d s \\
Candidemia, \\
Candida, Microbial \\
sensitivity tests, \\
Indoor patients \\
\hline Article Info \\
\hline $\begin{array}{l}\text { Accepted: } \\
\text { 04 August } 2019 \\
\text { Available Online: } \\
\text { 10 August } 2019\end{array}$ \\
\hline
\end{tabular}

\section{Introduction}

Candida species are known to be the most common fungal pathogens isolated from blood cultures. Candida ranks fourth in the United States and seventh in Europe. In recent years, the incidence of nosocomial Candida infections increased due to increasing number of patients receiving chemotherapy and other immunosuppressive therapies, innovations in
The aim of present study was to isolate, identify various species of Candida responsible for producing clinical Candidacies from blood culture and to determine antifungal susceptibility pattern of Candida species by disc diffusion method. study was conducted at Microbiology department P.D.U Medical college Rajkot from March 2014 to June 2015. Blood samples from suspected cases were inoculated in to Brain Heart Infusion broth were incubated at $37^{0 \mathrm{C}}$ and subcultured routinely. Whenever growth of white opaque colony on Blood agar was noticed, further processed to identify isolated yeast species by Gram's stain, germ-tube production, Hichrome and cornmeal agar morphology. Within the study period, among 38 candida strains isolated, Candida parapsilosilosis 17 (44.70\%), Candida guilliermondii 9 (23.68\%), Candida glabrata 6 (15.70\%), Candida tropicalis 4 (10.50\%), Candida albicans 2 (5.20\%). Antifungal susceptibility rates of candida isolates based on disc diffusion method were as follows: amphotericin B (100\%), voriconazole $(100 \%)$ and fluconazole $(97.2 \%)$. Candida species possess a number of virulence factors responsible for hematogenous disseminated infections in susceptible hosts with increased morbidity and mortality. Characterization of isolated Candida spp in bloodstream infection and any increase in resistance (if any) over time, must be determined with scientific methods. We think that similar studies will guide the clinician in planning treatment of candida infections especially in patients at risk. 
enable them to cause hematogenous disseminated infections in susceptible hosts with increased morbidity and mortality.

Due to differences in antifungal use and infection control strategies, distribution and antifungal susceptibility of Candida spp. Differ between countries and hospitals. In species other than Candida albicans, especially in Candida krusei and Candida glabrata resistance against azole group antifungal agents develops which further complicates choice of treatment in candidemias. Antifungal susceptibility tests guide the antifungal therapy during episodes of fungemia $(3,4)$.

In this study, our aim was to isolate, identify various species of Candida responsible for producing clinical Candidiasis from blood culture. And to determine antifungal susceptibility pattern of Candida species by disc diffusion method.

\section{Materials and Methods}

Candida species are known to be the most common fungal pathogens isolated from blood cultures. Candida ranks fourth in the United States and seventh in Europe. In recent years, the incidence of nosocomial Candida infections increased due to increasing number of patients receiving chemotherapy and other immunosuppressive therapies, innovations in transplantation surgery, use of broad-spectrum antibiotics, higher number of patients hospitalized in the intensive care units and invasive procedures performed on patients. Recent decades, there has been change in epidemiology of candida infection, characterized by progressive shift a predominance of Candida albicans to nonalbicans species. Candida species possess a number of virulence factors which enable them to cause hematogenous disseminated infections in susceptible hosts with increased morbidity and mortality.

Due to differences in antifungal use and infection control strategies, distribution and antifungal susceptibility of Candida spp. Differ between countries and hospitals. In species other than Candida albicans, especially in Candida krusei and Candida glabrata resistance against azole group antifungal agents develops which further complicates choice of treatment in candidemias. Antifungal susceptibility tests guide the antifungal therapy during episodes of fungemia.

In this study, our aim was to isolate, identify various species of Candida responsible for producing clinical Candidiasis from blood culture. And to determine antifungal susceptibility pattern of Candida species by disc diffusion method.

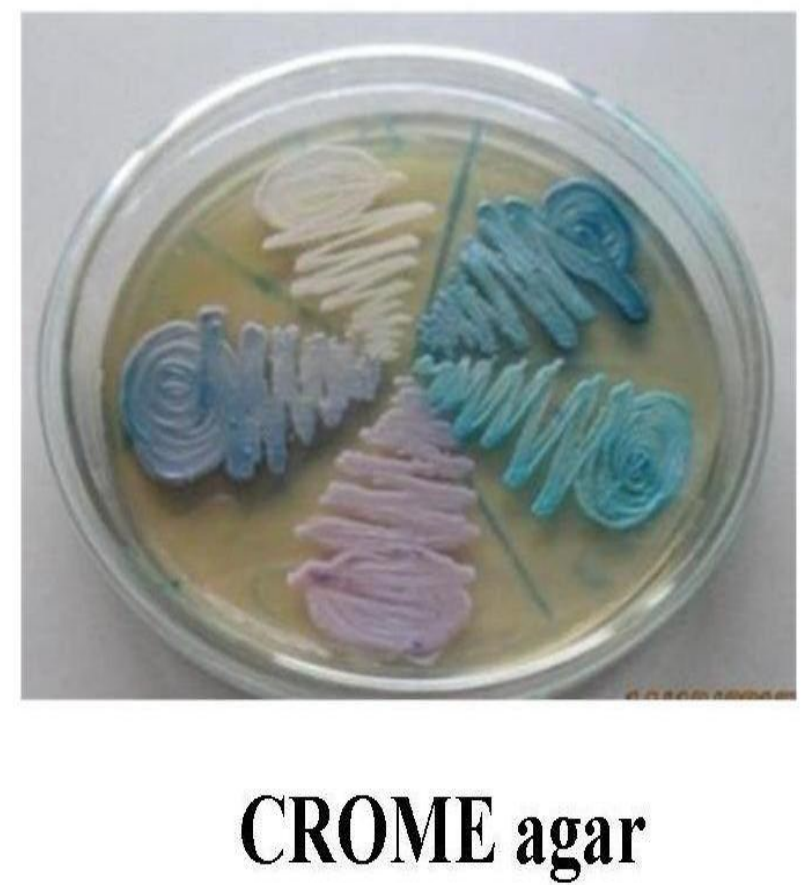




\section{Results and Discussion}

Table.1 Species wise distribution

\begin{tabular}{|l|c|l|}
\hline Isolated spp. & No. of Patients & Percentage \\
\hline C.albicans & 2 & $5.20 \%$ \\
\hline C.tropicalis & 4 & $10.5 \%$ \\
\hline C.guilliermondii & 9 & $23.68 \%$ \\
\hline C.parapsilosilosis & 17 & $44.70 \%$ \\
\hline C.glabrata & 6 & 15.70 \\
\hline Total & 38 & $100 \%$ \\
\hline
\end{tabular}

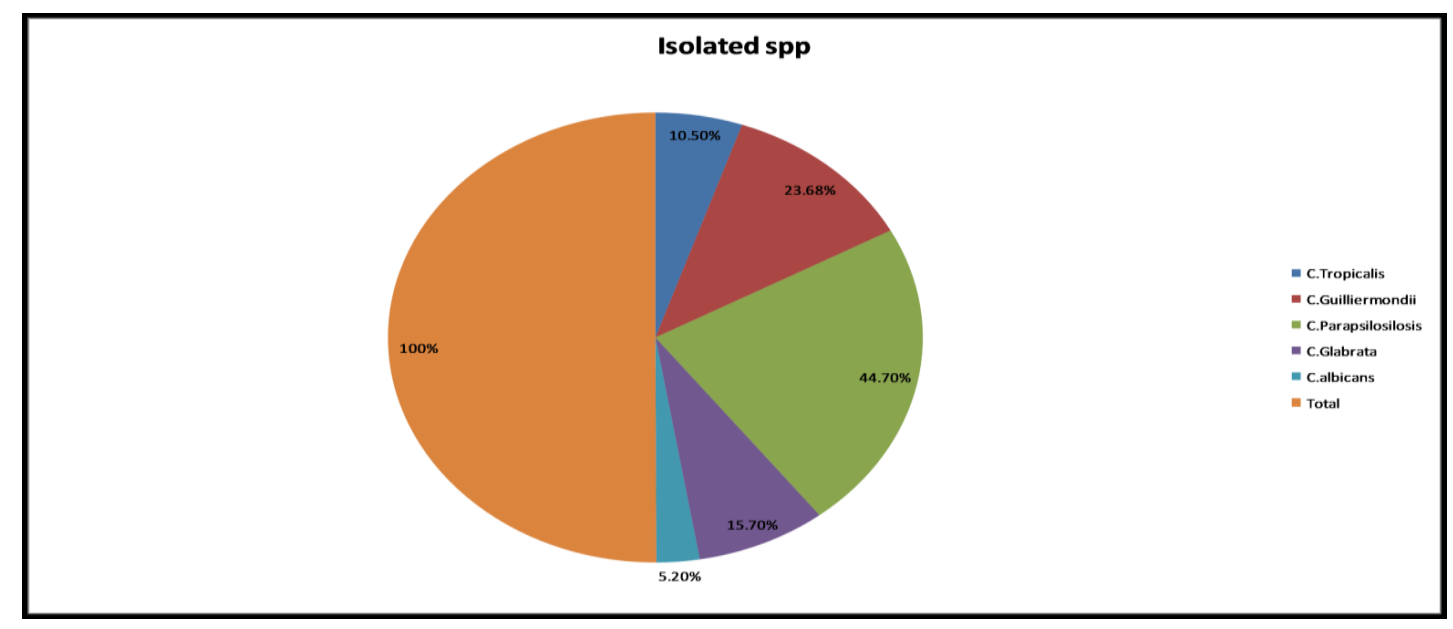

Table.2 Resistance patterns

\begin{tabular}{|l|l|l|l|l|}
\hline Isolated spp. & $\begin{array}{l}\text { No. of } \\
\text { Patients }\end{array}$ & Ap & FLC & VLC \\
\hline C.albicans & 2 & 0 & 0 & 0 \\
\hline Candida nonalbicans & 36 & 0 & $2.8 \%$ & 0 \\
\hline
\end{tabular}

Table.3 Age wise distribution

\begin{tabular}{|l|c|c|}
\hline Age & No. of Patients & Percentage \\
\hline Neonate & 35 & $92.1 \%$ \\
\hline Pediatric & 1 & $2.6 \%$ \\
\hline Adult & 2 & $5.26 \%$ \\
\hline Total & 38 & $100 \%$ \\
\hline
\end{tabular}


Table.4 Antifungal susceptibility patterns

\begin{tabular}{|l|l|l|l|l|l|l|l|}
\hline \multicolumn{2}{|c|}{} & \multicolumn{3}{c|}{ AP } & \multicolumn{3}{c|}{ FLC } \\
\hline Isolated spp. & Total & $\mathrm{S}(\%)$ & $\mathrm{I}(\%)$ & $\mathrm{R}(\%)$ & $\mathrm{S}(\%)$ & $\mathrm{I}(\%)$ & $\mathrm{R}(\%)$ \\
\hline C. albicans & $2(5.3 \%)$ & 100 & 0 & 0 & 100 & 0 & 0 \\
\hline Candida non albicans & $36(94.7 \%)$ & 72.2 & 27.8 & 0 & 97.2 & 0 & 2.8 \\
\hline
\end{tabular}

\begin{tabular}{|l|l|l|l|l|}
\hline & & \multicolumn{3}{|c|}{ VLC } \\
\hline Isolated spp & Total & $\mathrm{S}(\%)$ & $\mathrm{I}(\%)$ & $\mathrm{R}(\%)$ \\
\hline C. albicans & $2(5.3 \%)$ & 100 & 0 & 0 \\
\hline Candida nonalbicans & $36(94.7 \%)$ & 100 & 0 & 0 \\
\hline
\end{tabular}

In Present study most common isolated spp is Candida nonalbicans (94.7\%) compare to Candida albicans (5.3\%). Candida parapsilosis $(44.7 \%)$ is most commonly isolated nonalbicans spp. Out of 38 isolated candida spp 35(92.1\%) from Neonates, $1(2.6 \%)$ Pediatric and $2(5.26 \%)$ adult patients. Out of 35 neonates 16 were suffering either from low birth weight, preterm labor and/or RDS. C. albicans were found sensitive to all 3 drugs. In nonalbicans spp were found $2.8 \%$ resistant to flucanozole, $27.8 \%$ were intermediate to Amphotericin-B \& all are sensitive to Voriconazole.

In this study non albicans candida spp were common than Candida albicans and among them $C$. parapsilosis was most common.

Antifungal Resistance more common toward nonalbicans candida Neonates are at higher risk of developing candidemia.

Similar studies will guide the clinician in planning treatment of Candida infections especially in patients at risk (6-8).

\section{References}

1.Baradkar VP, Mathur M, Kumar S, Rathi M, Candida glabrata emerging pathogen in neonatal sepsis, Ann Trop Med Public Health, 1, 2008, 5-8.
2.Lunel FMV, Meis JFGM, Voss A (1999). Nosocomial Fungal Infections: Candidemia. Diagn. Microbiol. Infect. Dis. 34: 213-220.

3.Marchetti O, Bille J, Fluckiger U, Eggimann P, Ruef C, Garbino J, Calandra T, lauser MP, Täuber MG, Pittet D, Epidemiology of candidemia in Swiss tertiary care hospitals: secular trends, 1991-2000,ClinInfect Dis, 38(3), 2004, 311-320.

4.Martin D, Persat F, Piens MA, Picot S (2005). Candida species distribution in bloodstream cultures in Lyon, France, 1998-2001. Eur. J. Clin. Microbiol. Infect. Dis. 24:329-333.

5.Nurten Baran, Ismail Serkan Salman Typing of Candida species isolated from blood cultures and analysis of their in vitro antifungal susceptibilities, African Journal of Microbiology Research 7(41), 2013 pp. 4882-4885.

6.Pfaller MA, Diekema DJ (2004). Twelve years of fluconazole in clinical practice: global trends in species distribution and fluconazole susceptibility of bloodstream isolates of Candida. Clin. Microbiol. Infect. 10 Suppl 1:11-23.

7.Roilides E, Invasive candidiasis in neonates and children, Early Hum Dev, 87, 2011, S75S76.

8.Wisplinghoff H, Bischoff T, Tallent SM, Seifert H, Wenzel RP, Edmond MB, Nosocomial bloodstream infections in US hospitals: analysis of 24,179 cases from a prospective nationwide surveillance study, Clin Infect Dis, 39(3), 2004, 309-317. 


\section{How to cite this article:}

Meghagevariya and Ekta Gosaliya. 2019. Characterization of Isolated Candida Spp in Blood Stream Infection and its Antifungal Susceptibility Pattern. Int.J.Curr.Microbiol.App.Sci. 8(09): 638-642. doi: https://doi.org/10.20546/ijcmas.2019.809.076 